\title{
Review Article \\ Global Research Trends on Early-Life Feeding Practices and Early Childhood Caries: A Systematic Review
}

\author{
Benjamin W. Chaffee ${ }^{1}$ and Ashley Cheng ${ }^{2}$ \\ ${ }^{1}$ Center to Address Disparities in Children's Oral Health, Department of Preventive and Restorative Dental Sciences, \\ University of California San Francisco, Suite 495, 3333 California Street, San Francisco, CA 94143-1361, USA \\ ${ }^{2}$ Arthur A. Dugoni School of Dentistry, University of the Pacific, 2155 Webster Street, San Francisco, CA 94115, USA \\ Correspondence should be addressed to Benjamin W. Chaffee; benjamin.chaffee@ucsf.edu
}

Received 24 February 2014; Revised 29 April 2014; Accepted 3 May 2014; Published 19 May 2014

Academic Editor: Lin-P’ing Choo-Smith

Copyright (C) 2014 B. W. Chaffee and A. Cheng. This is an open access article distributed under the Creative Commons Attribution License, which permits unrestricted use, distribution, and reproduction in any medium, provided the original work is properly cited.

\begin{abstract}
Objective. To describe the epidemiologic literature related to early-life feeding practices and early childhood caries (ECC) with regard to publication attributes and trends in these attributes over time. Methods. Systematic literature review including electronic and manual searches (in BIOSIS, CINAHL, Cochrane Library, LILACS, MEDLINE, Web of Science, and WHOLIS), covering the years 1990-2013. Attributes of publications meeting a priori inclusion criteria were abstracted and organized by global region and trends over time. Attributes included country of origin and study design of included publications and age and caries prevalence of the populations studied. Results. 244 publications drawn from 196 independent study populations were included. The number of publications and the countries represented increased over time, although some world regions remained underrepresented. Most publications were cross-sectional (75\%); while this percentage remained fairly constant over time, the percentage of studies to account for confounding factors increased. Publications varied with respect to the caries experience and age range of children included in each study. Conclusions. Publication productivity regarding feeding practices and ECC research has grown, but this growth has not been evenly distributed globally. Individual publication attributes (i.e., methods and context) can differ significantly and should be considered when interpreting and synthesizing the literature.
\end{abstract}

\section{Introduction}

Early childhood caries (ECC) is a multifactorial disease [1], with early-life feeding practices as an appealing target for caries prevention. The American Academy of Pediatric Dentistry defines ECC as the presence of any primary tooth surface that is decayed, filled, or missing due to caries in a child under the age of six [2]. ECC is a potential source of pain, infection, and reduced quality of life for children and families $[3,4]$ and heightens the risk of dental caries in the permanent dentition $[5,6]$. Untreated caries in the primary dentition is one of the most common conditions globally [7], and as many as $60-90 \%$ of school-aged children worldwide experience dental caries [8].

Feeding habits for infants and young children play a contributory role in caries development $[9,10]$, and behaviors that limit added sugar, reduce bottle use, and serve defined meals or snacks have positive implications for oral health. Of particular relevance in settings where access to traditional dental care may be limited, feeding practices are potentially modifiable even without reliance on dental providers, and dental-healthy feeding practices could offer additional benefits, such as childhood obesity prevention [11]. Feeding practices can be integrated into oral health-general health interventions, a research priority for reducing or eliminating oral health inequalities [12].

Valid, representative evidence is essential for widely applicable guidelines and to bridge the translation gap from clinical and epidemiologic research to public health practice [12]. Yet, some authors have noted a relative lack of longitudinal and intervention studies of ECC and early-life feeding habits $[13,14]$. Also, given the prevalence of oral diseases in 
TABLE 1: Search terms used in electronic database search in MEDLINE.

Search terminology and syntax

(“dental caries" [MeSH Terms] OR (“dental” [All Fields] AND “caries” [All Fields]) OR "dental caries" [All Fields]) AND ((“diet” [MeSH Terms] OR "diet” [All Fields]) OR ("feeding behavior" [All Fields] OR "feeding behavior" [MeSH Terms] OR ("feeding” [All Fields] AND "behavior" [All Fields]) OR "feeding behavior" [All Fields]) AND ("1990/01/01" [PDAT]: "2013/12/31" [PDAT])) AND ( ("child" [MeSH Terms] OR "child" [All Fields]) OR ("infant" [MeSH Terms] OR "infant" [All Fields]) OR ("child" [MeSH Terms] OR "child” [All Fields] OR "children" [All Fields]) OR preschool [All Fields] OR ("pediatrics" [MeSH Terms] OR "pediatrics" [All Fields] OR "pediatric" [All Fields]))

Date completed: November 1, 2013

many lower-resource countries [8], oral health promotion strategies would ideally incorporate evidence drawn from such settings. Understanding heterogeneity across studies is vital for determining the appropriateness of pooling results drawn from different contexts. Finally, identifying trends in ECC research over time might inform future investigative priorities by highlighting any existing research gaps.

The objective of this systematic review is to characterize the epidemiologic literature connecting early-life feeding practices and ECC. Specifically, this review aims to (1) describe the relevant literature, published from 1990 to 2013, regarding global representation and study attributes and (2) evaluate trends in the literature during this period.

\section{Method}

2.1. Systematic Literature Search. Electronic searches, concluded in November 2013, were conducted in the BIOSIS, CINAHL, Cochrane Library, LILACS, MEDLINE, Web of Science, and WHOLIS bibliographic databases, limited to publication dates from 1990. The MEDLINE search used Medical Subject Headings (MeSH) terminology (Table 1); analogous searches were adapted for other databases. Search terms were in English, but without explicit language restrictions.

Inclusion and exclusion criteria were developed before reviewing citations. This review focused on the epidemiologic literature, broadly defined as all studies based in human populations, whether observational or experimental, but not laboratory or animal-based research. Excluded were abstracts, dissertations, conference proceedings, commentaries, review articles, position statements, and practice guidelines. Inclusion required a clinical caries assessment in a pediatric population (i.e., primary dentition), rather than participant-reported status, oral hygiene, oral bacterial infection, or dental service utilization. Studies must have featured both caries-positive and caries-free individuals. Feeding practices could relate to current or past diet or habits, including measures of eating frequency, bottle use, breastfeeding, intake of specific foods or nutrients, food types (e.g., sweets), pacifier use, utensil sharing, or nocturnal feeding. Excluded were ecological diet measures, nutritional status measures (e.g., anthropometry and enamel defects), medication use, biomarkers, or maternal diet. Intervention studies were eligible if intervention components related to feeding or diet but not in a combined intervention with other factors, such as oral hygiene, fluoride, or restorative treatment. Inclusion required a reported measure of association (or data permitting its calculation) between at least one feeding practice and caries (e.g., prevalence ratio). Studies reporting only results of statistical tests (e.g., $P$ values) without expressing the magnitude of association were excluded. Only publications for which full-text copies could be obtained in English, Portuguese, or Spanish were considered.

Two reviewers (BC and AC) independently assessed identified citations and, later, full-text copies of citations deemed potentially relevant based on titles and abstracts. For any citation selected by only one reviewer, both reviewers discussed the article to reach consensus regarding inclusion. Additionally, a manual search applied the same inclusionexclusion criteria to the citation lists of reviewed full-text publications. Relevant characteristics of included studies were abstracted to standardized forms (Table 2). Publications were considered drawn from a single independent study if results were derived from the same or overlapping participants (e.g., a national survey).

2.2. Study Attributes. Country of origin refers to participant recruitment, not necessarily authors' home country. For this review, cross-sectional design applies to any study in which feeding practice and caries data were collected simultaneously, regardless of whether investigators asked participants to recall past events or if investigators applied different sampling fractions to caries-positive and caries-free children. Longitudinal design applies to studies with data from two or more time points, in which the observed feeding practices could be related to future caries. In intervention studies, investigators assigned a feeding-related treatment or intervention to a subgroup of participants, along with an appropriate control group. When possible, sample size refers to those individuals included in results, not necessarily all participants initially recruited.

A study was considered peer-reviewed if its journal was designated "refereed" at Ulrichsweb directory (http://ulrichsweb.serialssolutions.com/) or if the journal's website described the peer-review process. A study was deemed to have accounted for confounding variables if it included multivariable statistical adjustment, stratification for nonfeeding variables, or was a randomized controlled trial. To assess trends over time, included publications were grouped into three 8-year periods: 1990-1997, 1998-2005, and 2006-2013. 
TABLE 2: Data abstraction form.

(a) Publication characteristics: search

\begin{tabular}{|c|c|c|c|c|}
\hline $\begin{array}{l}\text { ID number } \\
\text { (assigned by } \\
\text { reviewers) }\end{array}$ & First author & Year of publication & Journal & Language \\
\hline $\begin{array}{l}\text { Peer review } \\
\text { (yes/no) }\end{array}$ & $\begin{array}{l}\text { Meets inclusion } \\
\text { criteria }\end{array}$ & $\begin{array}{l}\text { Reason for } \\
\text { exclusion, if } \\
\text { applicable }\end{array}$ & $\begin{array}{l}\text { Identification } \\
\text { method (electronic } \\
\text { or hand search) }\end{array}$ & $\begin{array}{l}\text { ID number of other publications } \\
\text { based on the same study } \\
\text { population }\end{array}$ \\
\hline
\end{tabular}

(b) Publication characteristics: design and study population

\begin{tabular}{lcc}
\hline $\begin{array}{l}\text { Study design (e.g., } \\
\text { cross-sectional, longitudinal, } \\
\text { and intervention) }\end{array}$ & Country of origin & WHO region \\
\hline $\begin{array}{l}\text { Follow-up percentage, if } \\
\text { applicable }\end{array}$ & Child age at baseline (mean, range) & $\begin{array}{c}\text { Child age at follow-up (mean, } \\
\text { range), if applicable }\end{array}$ \\
\hline
\end{tabular}

(c) Caries outcomes

\begin{tabular}{|c|c|c|c|c|c|}
\hline $\begin{array}{l}\text { Examination } \\
\text { method (e.g., } \\
\text { WHO field } \\
\text { manual) }\end{array}$ & $\begin{array}{l}\text { Caries prevalence, } \\
\text { including } \\
\text { noncavitated decay }\end{array}$ & $\begin{array}{c}\text { Caries prevalence, } \\
\text { cavitated decay } \\
\text { only }\end{array}$ & Mean dmfs & Mean dmft & Other measures \\
\hline
\end{tabular}

(d) Statistical methods and results

\begin{tabular}{lccc}
\hline $\begin{array}{l}\text { Measure of association } \\
\text { reported }\end{array}$ & $\begin{array}{c}\text { Adjustment method for } \\
\text { confounding }\end{array}$ & Main findings & Other notes \\
\hline
\end{tabular}

Information from studies under consideration for review was entered into a spreadsheet with the column headings listed above.

WHO: World Health Organization.

$\mathrm{dmfs} / \mathrm{t}$ : decayed missing (due to caries) filled primary surface/tooth index.

\section{Results and Discussion}

3.1. Results. The electronic literature search yielded 2635 hits, of which 1852 represented nonduplicate citations (Figure 1). Of these, 421 potentially relevant citations were designated for full-text review. Hand searching identified an additional 33 potentially relevant citations. From the combined 454 potentially relevant citations, 244 publications drawn from 196 independent study populations met inclusion criteria (citations available on request).

The total number of publications and the number of countries represented both increased over time (Table 3). Of the six World Health Organization (WHO) regions, the most independent studies originated from the Americas, Europe, and Western Pacific; fewer studies were conducted in Africa, the Eastern Mediterranean, or Southeast Asia (Figure 2). The sources of publications shifted over time. From 1990 to 1997, the most represented countries were the United States $(N=$ $9)$, Sweden $(N=8)$, Finland $(N=7)$, and the United Kingdom $(N=7)$, accounting for $57 \%$ (31/54) of publications during that period. No included publication dated earlier than 1998 was from Brazil. Since 1998, Brazil produced the most publications of any country $(N=37)$, followed by the United States $(N=36)$, China $(N=16)$, and India $(N=10)$. Restricted to English-language publications, Brazil still accounted for 14\% (24/177) of all included publications since 1998.

The most common study design was cross-sectional, accounting for $75 \%(182 / 244)$ of included publications
(Table 3). Only nine publications, drawn from seven independent studies, were interventional in design. The percentage of cross-sectional studies was similar over time as was the percentage of publications that underwent some form of peer-review, which was $>94 \%$ in all time periods (Table 3 ). In more recent time periods, a greater percentage of publications presented results adjusted for putative confounding variables (Table 3).

Although all studies pertained to children in the primary dentition, the study populations differed considerably with respect to caries status (Figure 3 ) and age range (Figure 4) of the children in each study. In all WHO regions, there were studies representing populations of very low caries burden and populations of very high caries burden. Likewise, some studies featured populations of children within a narrow age range (either younger or older), while other studies were more inclusive, featuring children ranging in age from infancy to near school age. It was not possible to make country- or regionwide estimates of caries prevalence because most study populations were not intended to be nationally representative.

3.2. Discussion. The body of literature relating early-life feeding practices and early childhood caries is large, heterogeneous, and increasing over time. While this increase could be partly attributable to broader electronic indexing of more recent publications, this growth also reflects a general trend of rising publication productivity in the health sciences $[15,16]$. 


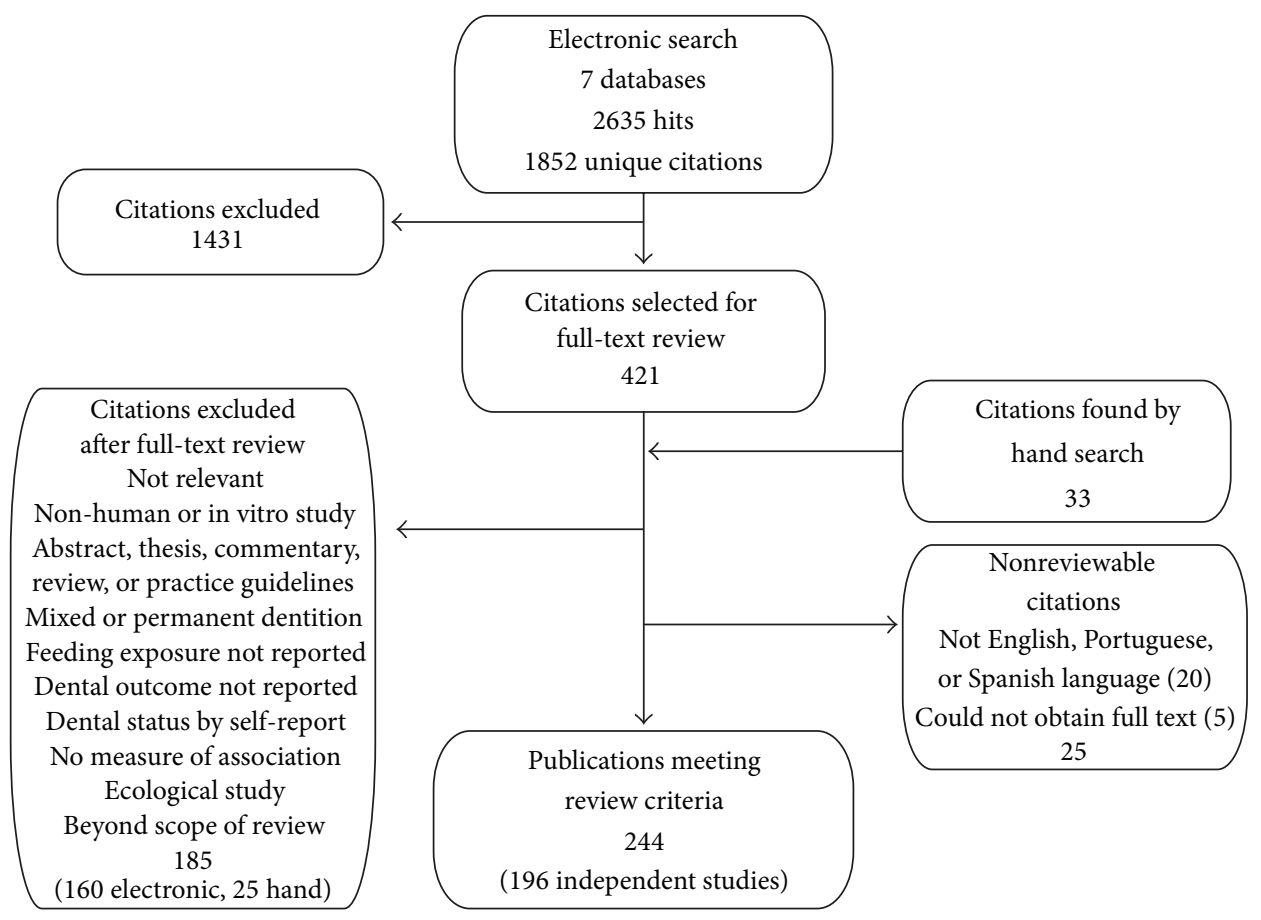

FIGURE 1: Flow diagram of systematic literature search.

TABLE 3: Attributes of publications meeting review inclusion criteria.

\begin{tabular}{|c|c|c|c|c|}
\hline & $\begin{array}{c}\text { Overall } \\
N=244\end{array}$ & $\begin{array}{c}1990-1997 \\
N=54\end{array}$ & $\begin{array}{c}1998-2005 \\
N=79\end{array}$ & $\begin{array}{c}2006-2013 \\
N=111\end{array}$ \\
\hline Countries represented & 47 & 19 & 23 & 34 \\
\hline Sample size ${ }^{1}$ & 295 & 245 & 249 & 375 \\
\hline Median (range) & $(30-13,889)$ & $(43-3000)$ & $(41-4236)$ & $(30-13,889)$ \\
\hline \multicolumn{5}{|l|}{ Study design $^{2}$} \\
\hline Cross-sectional & $182(75 \%)$ & $39(72 \%)$ & $63(80 \%)$ & $80(72 \%)$ \\
\hline Longitudinal & $51(21 \%)$ & $14(26 \%)$ & $13(16 \%)$ & $24(22 \%)$ \\
\hline Intervention & $9(4 \%)$ & $1(2 \%)$ & $2(3 \%)$ & $6(5 \%)$ \\
\hline Peer reviewed & $232(95 \%)$ & $53(98 \%)$ & $74(94 \%)$ & $105(95 \%)$ \\
\hline Adjusted for confounding & $141(58 \%)$ & $17(31 \%)$ & $45(57 \%)$ & $79(71 \%)$ \\
\hline
\end{tabular}

This century, we observed that the number of publications related to feeding practices and caries that originated from some countries expanded, notably from Brazil, China, and India, which, along with the United States, comprised the four most-represented countries in terms of publications since 1998.

Other studies of country-level production in the dental sciences spanning 1999-2003 [17] and in orofacial pain research during 2004-2005 [18] both found the United States, Japan, and the United Kingdom to be the three countries most represented in those fields and time periods. Importantly, these prior assessments assigned publications' countries of origin as the home countries of the study coauthors. By our methodology, the source of study participants determined the originating country, highlighting the location to which study results would be most generalizable, even for research conducted as an international partnership. Furthermore, our findings could indicate an accentuated rise in oral health research in certain countries in the 8-10 years since these earlier assessments or could reflect a special emphasis on population-based early childhood caries research. In Brazil, for example, the observed increase in publication productivity follows a rapid expansion in dental training opportunities, where more than 100 new dental schools opened nationally from 1995 to 2008 [19]. Additionally, recent efforts to integrate behavioral and population-based sciences into dental 

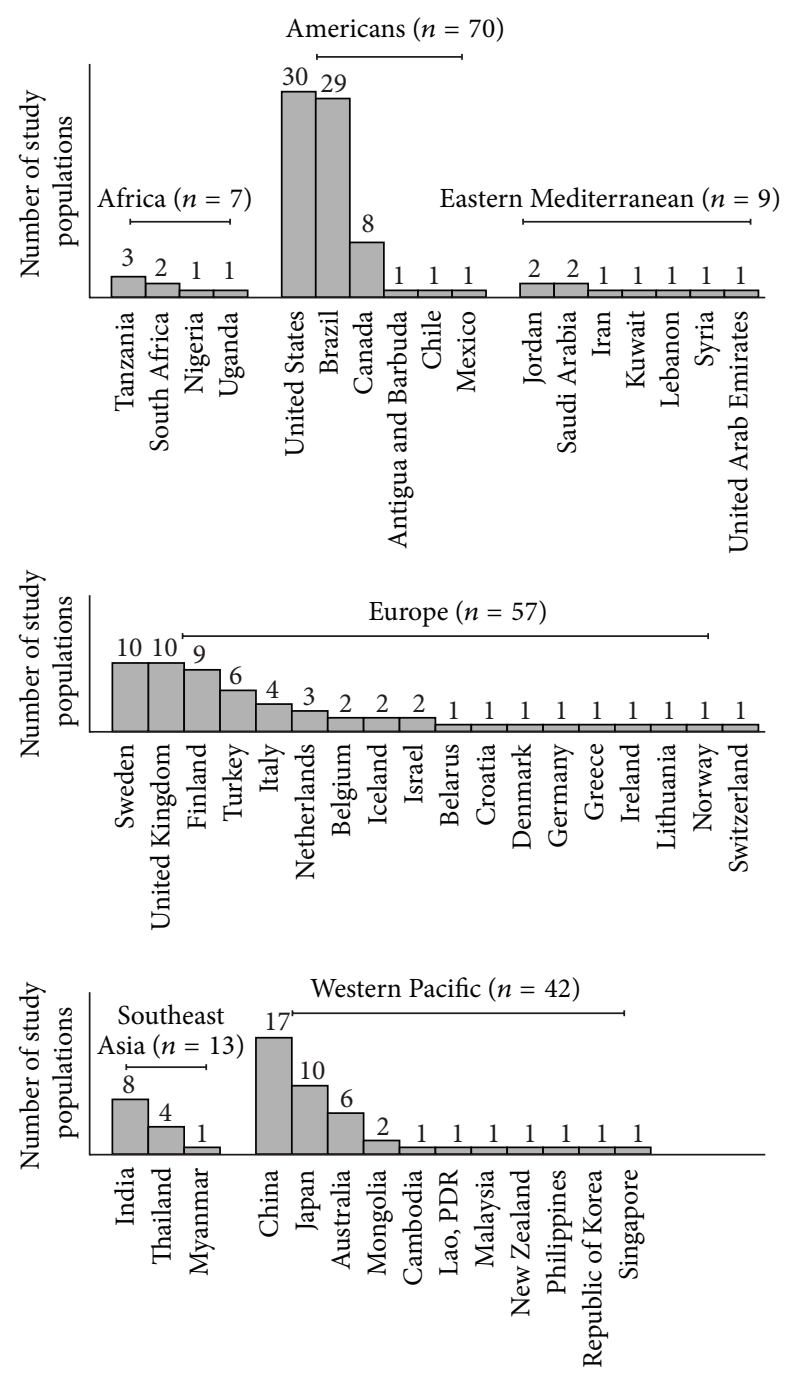

FIGURE 2: Independent study populations by country and by World Health Organization region. The number of studies sums to 198, rather than 196, because two studies recruited participants from two countries; one study included participants from Finland and Tanzania and another study included participants from Tanzania and Uganda.

education programs in China may have contributed to new opportunities for community-based research [20].

In contrast, many world regions, specifically Africa, the Eastern Mediterranean, and Southeast Asia, remain largely underrepresented in the literature, despite shouldering a disproportionate caries burden [8]. It is possible that the language restrictions of this review might have excluded some number of otherwise relevant publications from these regions. However, the number of identified citations that were excluded for language reasons was much smaller than the size of the publication gap between global regions. More high quality studies are needed from underrepresented world regions to inform comprehensive, globally representative policy and practice recommendations.

The cross-sectional design was used extensively, limiting the ability of many studies to distinguish the temporal

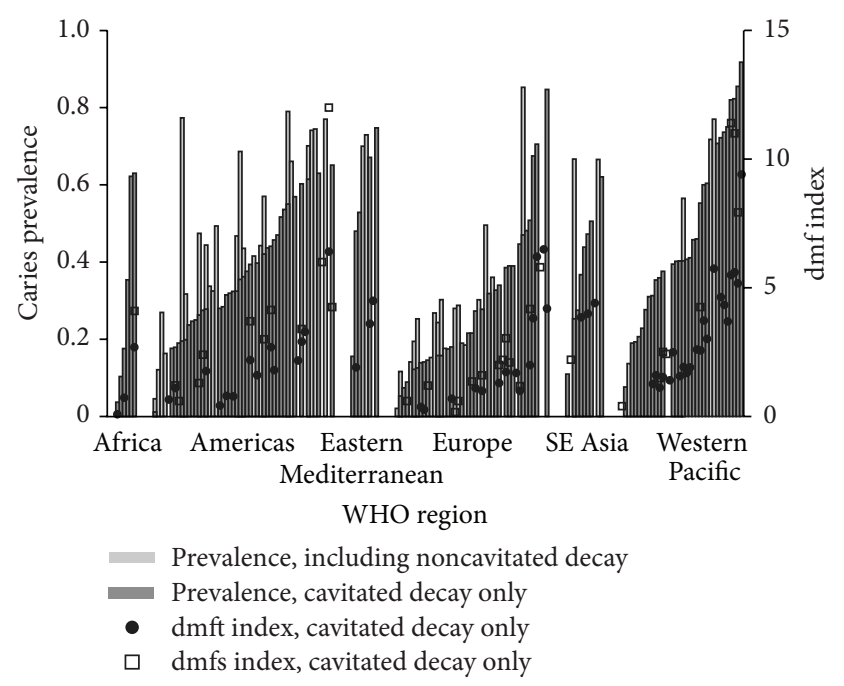

FIgure 3: Child caries status by study and by World Health Organization region. The caries prevalence (if provided) and mean number of affected teeth or surfaces (if provided) of the children who contributed data to each independent study are shown. The $\mathrm{dmft}$ and $\mathrm{dmfs}$ indices exclude noncavitated lesions. Within each region, study populations are ranked from the most dentally healthy (left) to the least. dmfs/t: decayed missing (due to caries) filled primary surface/tooth index.

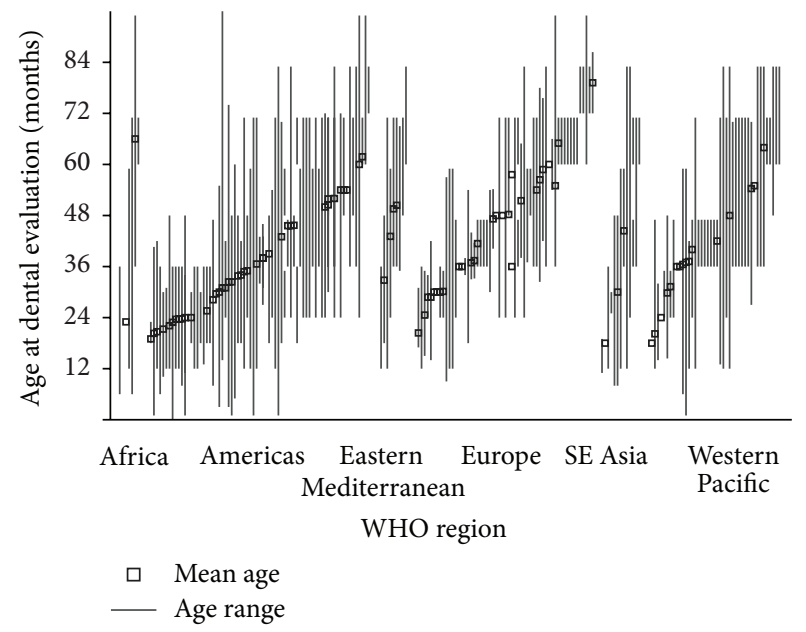

Figure 4: Age of participants by study and by World Health Organization region. The mean age (if provided) and age range (if provided) of the children who contributed data to each independent study are shown. Within each region, study populations are ranked from the youngest (left) to the oldest.

ordering between current feeding practices and caries. Many studies relied on maternal recall of past feeding practices, the accuracy of which depends on the length of the recall period and the practice being recalled [21]. Despite these disadvantages, cross-sectional studies are generally more expedient and less costly than longitudinal studies and, therefore, could aid hypothesis generation for subsequent longitudinal investigations. 
The relationship between food intake and caries is not a novel area of study [22], yet translation of research findings into effective practice is a persistent implementation gap [12]. This review identified few standalone feeding practice interventions, consisting of just seven trials. While not all of these interventions yielded significant dental health effects, several exemplified a common-risk factor approach to disease prevention, investigating oral health outcomes downstream of nutritional or otherwise general health-focused interventions [23-27].

The percentage of publications using methods to account for confounding factors increased with time. While this can be considered a positive development, it does necessarily indicate that the adjustment methods used were appropriate or comprehensive. For example, inclusion of variables in statistical models as confounding factors without reasonable evidence to suggest such variables plays a confounding role which may actually increase bias [28]. Furthermore, it is not known to what extent publication bias, the greater tendency for statistically significant findings to enter the literature [29], affected the trends observed in this review.

Heterogeneity across studies can be informative and must be considered in combining study results [30]. In addition to geographic heterogeneity, differences in the age range and caries experience of different populations highlight reasons for caution if pooling results. For example, feeding practices such as bottle use and breastfeeding are strongly related to age, as is ECC, and, therefore, age distributions must be considered during analysis and interpretation of epidemiological data. Studies might find inverse relationships between certain feeding practices and caries if those practices predominate among younger children. Additionally, relative measures of association, such as the prevalence ratio, are a function of the disease level in the comparison group and, thus, might not be equivalent across populations that vary widely in baseline disease levels. For example, a reported relative risk of 1.5 that relates caries prevalence across groups exposed or unexposed to a particular feeding practice might have different practical implications if the prevalence levels being compared are $8 \%$ to $12 \%$ versus $40 \%$ to $60 \%$.

The scope of this review was limited to papers published since 1990. It cannot be assumed that any trends identified can be extrapolated to earlier periods. As a limitation, this review tracked trends in a number of objective study attributes but did not perform a specific assessment of the risk of bias or the inherent quality of the individual studies and cannot be used as an assessment of study quality over time. While the observed increase in the percentage of studies to account for confounding factors is encouraging and likely to be correlated with study quality, this observation alone does not necessarily demonstrate that the overall quality of studies has improved generally.

The number of publications on feeding practices and ECC has increased, suggesting growing interest in the topic. In counting research productivity as publication counts, without weights for quality or impact, however, this review characterized the literature in broad strokes, identifying gaps generally as they relate to geographic representation and longitudinal evidence. In future analyses, a systematic synthesis of the findings contained in this literature is needed. Ultimately, the translation of identified associations between feeding practices and caries into effective oral health promoting practice will necessarily recognize the interlacing of feeding practices with other caries determinants, such as socioeconomic influences [31], parental factors [32], and other political, economic, social, and community contributions to oral health [33].

\section{Conclusions}

The number of publications reporting on early-life feeding practices and ECC has expanded, with increasing representation from some countries (e.g., Brazil, China, and India) but remaining underrepresentation from others (e.g., African region). Most studies to date have been cross-sectional in design; more high quality longitudinal and intervention studies would provide stronger evidence to inform practice and policy. Publication attributes (i.e., methods and context) can differ significantly by individual publication and should be considered in the interpretation and synthesis of the literature. Integration of multidisciplinary knowledge, including future methodologically rigorous studies from less represented world regions, is needed to address the significant worldwide burden of early childhood caries.

\section{Conflict of Interests}

The authors declare that there is no conflict of interests regarding the publication of this paper.

\section{Acknowledgment}

This research was made possible by NIH/NIDCR Grants F30DE022208 and U54DE019285.

\section{References}

[1] N. Tinanoff and S. Reisine, "Update on early childhood caries since the Surgeon General's report," Academic Pediatrics, vol. 9, no. 6, pp. 396-403, 2009.

[2] American Academy on Pediatric Dentistry, American Academy of Pediatrics, "Policy on Early Childhood Caries (ECC): classifications, consequences, and preventive strategies," Pediatric Dentistry, vol. 30, supplement, no. 7, pp. 40-43, 2008.

[3] J. Abanto, T. S. Carvalho, F. M. Mendes, M. T. Wanderley, M. Bönecker, and D. P. Raggio, "Impact of oral diseases and disorders on oral health-related quality of life of preschool children," Community Dentistry and Oral Epidemiology, vol. 39, no. 2, pp. 105-114, 2011.

[4] P. F. Kramer, C. A. Feldens, S. H. Ferreira, J. Bervian, P. H. Rodrigues, and M. A. Peres, "Exploring the impact of oral diseases and disorders on quality of life of preschool children," Community Dentistry and Oral Epidemiology, vol. 41, pp. 327335, 2013.

[5] A. L. Greenwell, D. Johnsen, T. A. DiSantis, J. Gerstenmaier, and N. Limbert, "Longitudinal evaluation of caries patterns form the primary to the mixed dentition," Pediatric Dentistry, vol. 12, no. 5, pp. 278-282, 1990. 
[6] Y. Li and W. Wang, "Predicting caries in permanent teeth from caries in primary teeth: an eight-year cohort study," Journal of Dental Research, vol. 81, no. 8, pp. 561-566, 2002.

[7] W. Marcenes, N. J. Kassebaum, E. Bernabé et al., "Global burden of oral conditions in 1990-2010: a systematic analysis," Journal of Dental Research, vol. 92, no. 7, pp. 592-597, 2013.

[8] P. E. Petersen, D. Bourgeois, H. Ogawa, S. Estupinan-Day, and C. Ndiaye, "The global burden of oral diseases and risks to oral health," Bulletin of the World Health Organization, vol. 83, no. 9, pp. 661-669, 2005.

[9] R. H. Selwitz, A. I. Ismail, and N. B. Pitts, "Dental caries," The Lancet, vol. 369, no. 9555, pp. 51-59, 2007.

[10] C. Mobley, T. A. Marshall, P. Milgrom, and S. E. Coldwell, “The contribution of dietary factors to dental caries and disparities in caries," Academic Pediatrics, vol. 9, no. 6, pp. 410-414, 2009.

[11] K. A. Spiegel and C. A. Palmer, "Childhood dental caries and childhood obesity. Different problems with overlapping causes," American Journal of Dentistry, vol. 25, no. 1, pp. 59-64, 2012.

[12] N. Pitts, B. Amaechi, R. Niederman et al., "Global oral health inequalities: dental caries task group-research agenda," Advances in Dental Research, vol. 23, no. 2, pp. 211-220, 2011.

[13] R. Harris, A. D. Nicoll, P. M. Adair, and C. M. Pine, "Risk factors for dental caries in young children: a systematic review of the literature," Community Dental Health, vol. 21, no. 1, pp. 71-85, 2004.

[14] R. Valaitis, R. Hesch, C. Passarelli, D. Sheehan, and J. Sinton, “A systematic review of the relationship between breastfeeding and early childhood caries," Canadian Journal of Public Health, vol. 91, no. 6, pp. 411-417, 2000.

[15] M. J. Boschen, "Publication trends in individual anxiety disorders: 1980-2015," Journal of Anxiety Disorders, vol. 22, no. 3, pp. 570-575, 2008.

[16] J. P. Deshazo, D. L. Lavallie, and F. M. Wolf, "Publication trends in the medical informatics literature: 20 years of "medical informatics" in MeSH," BMC Medical Informatics and Decision Making, vol. 9, no. 1, article 7, 2009.

[17] J. A. Gil-Montoya, J. Navarrete-Cortes, R. Pulgar, S. Santa, and F. Moya-Anegón, "World dental research production: an ISI database approach (1999-2003)," European Journal of Oral Sciences, vol. 114, no. 2, pp. 102-108, 2006.

[18] C. Robert, N. Caillieux, C. S. Wilson, J. Gaudy, and C. Arreto, "World orofacial pain research production: a bibliometric study (2004-2005)," Journal of Orofacial Pain, vol. 22, no. 3, pp. 181$189,2008$.

[19] N. A. Saliba, S. A. S. Moimaz, C. A. S. Garbin, and D. G. Diniz, "Dentistry in Brazil: its history and current trends," Journal of Dental Education, vol. 73, no. 2, pp. 225-231, 2009.

[20] C. Huang, Z. Bian, B. Tai, M. Fan, and C. Kwan, "Dental education in Wuhan, China: challenges and changes," Journal of Dental Education, vol. 71, no. 2, pp. 304-311, 2007.

[21] R. Li, K. S. Scanlon, and M. K. Serdula, "The validity and reliability of maternal recall of breastfeeding practice," Nutrition Reviews, vol. 63, no. 4, pp. 103-110, 2005.

[22] A. Stewart, "Why dental caries is so general, and how to prevent it," British Medical Journal, vol. 2, no. 877, pp. 560-562, 1877.

[23] B. W. Chaffee, C. A. Feldens, and M. R. Vítolo, "Clusterrandomized trial of infant nutrition training for caries prevention," Journal of Dental Research, vol. 92, supplement, no. 7, pp. 29S-36S, 2013.
[24] C. A. Feldens, E. R. J. Giugliani, Á. Vigo, and M. R. Vítolo, "Early feeding practices and severe early childhood caries in four-yearold children from southern Brazil: a birth cohort study," Caries Research, vol. 44, no. 5, pp. 445-452, 2010.

[25] S. Karjalainen, L. Sewón, E. Söderling, H. Lapinleimu, R. Seppänen, and O. Simell, "Oral health of 3-year-old children and their parents after 29 months of child-focused antiatherosclerotic dietary intervention in a prospective randomized trial," Caries Research, vol. 31, no. 3, pp. 180-185, 1997.

[26] M. S. Kramer, I. Vanilovich, L. Matush et al., "The effect of prolonged and exclusive breast-feeding on dental caries in rarly school-age children: new evidence from a large randomized trial," Caries Research, vol. 41, no. 6, pp. 484-488, 2007.

[27] A. Scheiwe, R. Hardy, and R. G. Watt, "Four-year follow-up of a randomized controlled trial of a social support intervention on infant feeding practices," Maternal and Child Nutrition, vol. 6, no. 4, pp. 328-337, 2010.

[28] A. T. Merchant and W. Pitiphat, "Directed acyclic graphs (DAGs): an aid to assess confounding in dental research," Community Dentistry and Oral Epidemiology, vol. 30, no. 6, pp. 399-404, 2002.

[29] R. Light and D. Pillemer, Summing up: The Science of Reviewing Research, Harvard University Press, Cambridge, Mass, USA, 1984.

[30] S. Greenland, "Invited commentary: a critical look at some popular meta-analytic methods," American Journal of Epidemiology, vol. 140, no. 3, pp. 290-296, 1994.

[31] M. A. da Fonseca, “The effects of poverty on children's development and oral health," Pediatric Dentistry, vol. 34, no. 1, pp. 32-38, 2012.

[32] M. Hooley, H. Skouteris, C. Boganin, J. Satur, and N. Kilpatrick, "Parental influence and the development of dental caries in children aged 0-6 years: a systematic review of the literature," Journal of Dentistry, vol. 40, no. 11, pp. 873-885, 2012.

[33] J. Lee and K. Divaris, "The ethical imperative of addressing oral health disparities: a unifying framework," Journal of Dental Research, vol. 93, no. 3, pp. 224-230, 2014. 


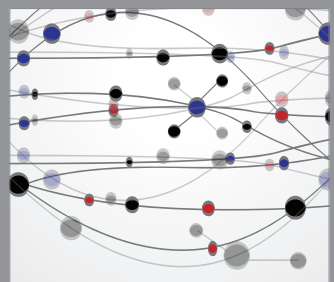

The Scientific World Journal
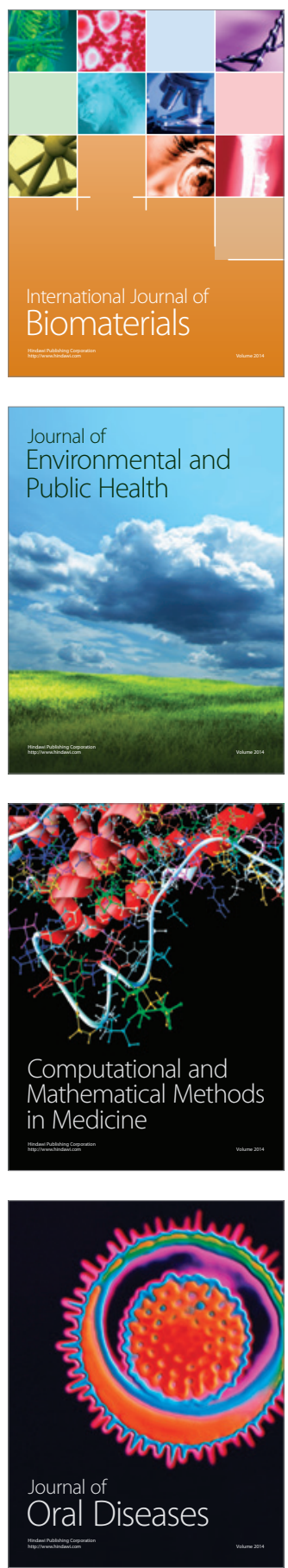
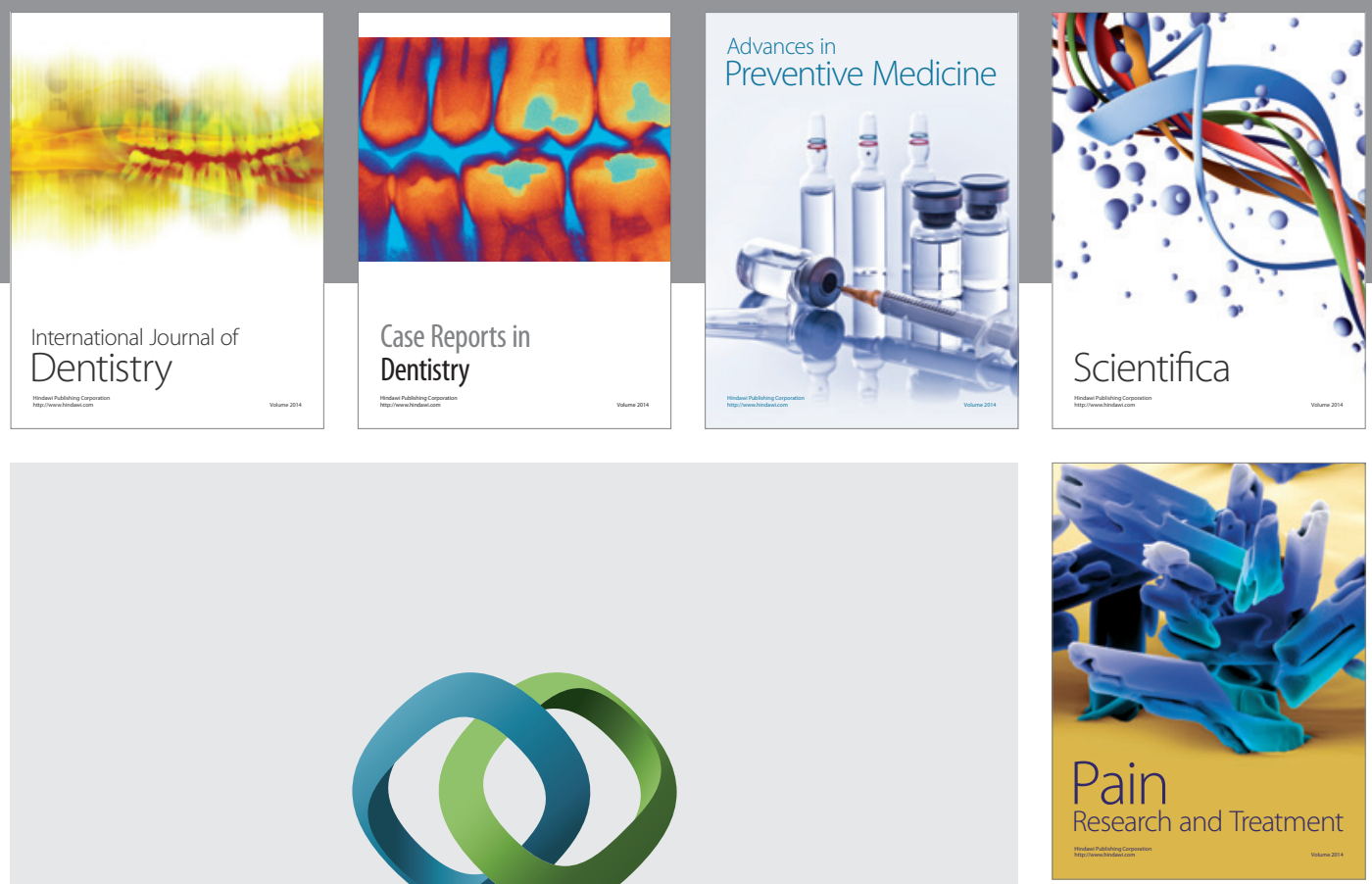

\section{Hindawi}

Submit your manuscripts at

http://www.hindawi.com
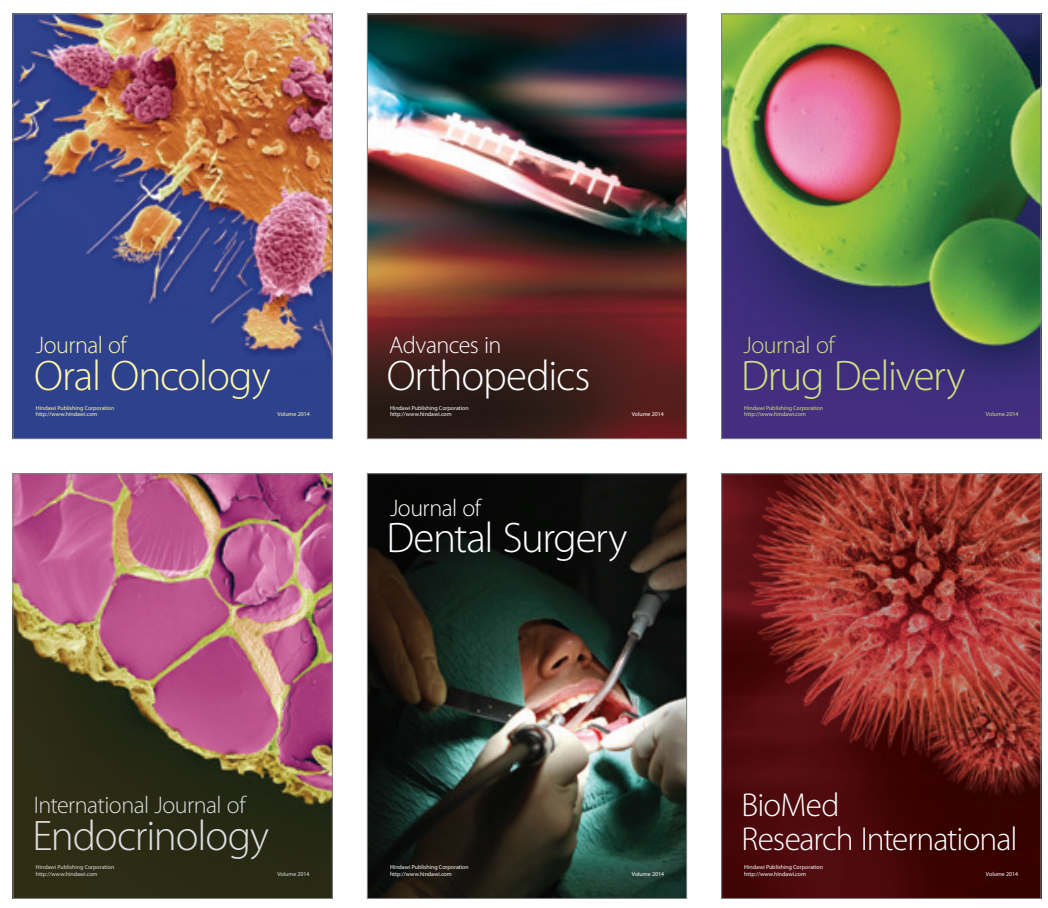

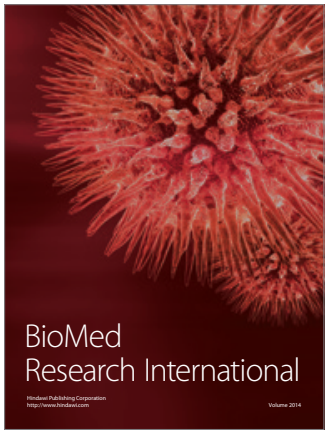

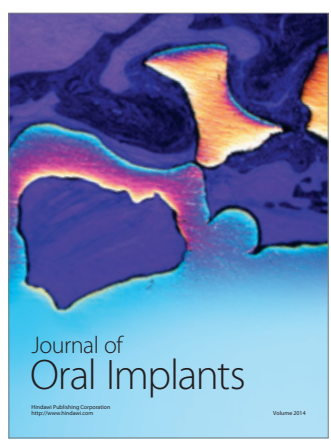
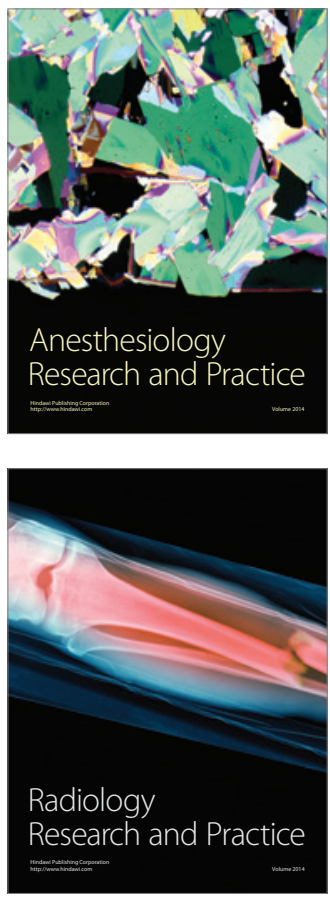